\title{
Risk factor for Mycobacterium leprae detection in household contacts with leprosy patients: a study in Papua, East Indonesia
}

Hana Krismawati, Antonius Oktavian, Yustinus Maladan, Tri Wahyuni

pISSN: 0853-1773 • elSSN: 2252-8083 https://doi.org/10.13181/mji.oa.192962 Med J Indones. 2020;29:64-70

Received: June 29, 2018

Accepted: October 8, 2019

Authors' affiliations:

Department of Microbiology, National Institute of Health Research and Development of Papua, Jayapura, Indonesia

\section{Corresponding author:}

Hana Krismawati

Department of Microbiology, National Institute of Health Research and Development of Papua, Jalan Ahmad Yani No. 48, North Jayapura 99111,

Papua, Indonesia

Tel/Fax: +62-967-534389/

+62-967-534697

E-mail: hkrismawati@gmail.com

\begin{abstract}
BACKGROUND In the era of leprosy eradication, Jayapura is still one of the biggest leprosy pockets in Papua, Indonesia. The trend for leprosy case detection rate has remained relatively stable over recent years. This study was aimed to detect Mycobacterium leprae in household contacts and to evaluate the associated factors with the detection.
\end{abstract}

METHODS This cross-sectional study recruited household contacts of leprosy patients who were diagnosed consecutively from March to August 2015 in Hamadi Point of Care, Jayapura. The leprosy patients were diagnosed using polymerase chain reaction (PCR). For each leprosy patient, up to four household contacts that had no symptom were included. Every household contact received screening through DNA detection of $M$. leprae extracted from nasal swab specimens and examined using PCR. Factors for bacteria detection included intensity, time duration and number of contacts living together in the same house, and random blood glucose levels were evaluated. Bivariate analysis was used to associate them with $M$. leprae detection in household contacts.

RESULTS From 107 household contacts of 35 patients who had leprosy, M. leprae was detected in $19.6 \%$. Household contacts with leprosy patients for $>1$ year was a risk factor for detection $(\mathrm{OR}=12.45 ; 95 \% \mathrm{Cl}=1.595-97.20 ; p=0.002)$. Blood glucose $(p=0.444)$, ethnic $(p=0.456)$, sleeping proximity to leprosy case $(p=0.468)$ and relatives $(p=$ 0.518 ) give no effect to $M$. leprae detection in household contacts.

CONCLUSIONS Among the various risk factors studied, duration of living together with the patient significantly increased the risk of $M$. leprae transmission.

KEYWORDS households, leprosy, Mycobacterium leprae, polymerase chain reaction
According to the World Health Organization (WHO) reports, Indonesia ranked third in world leprosy endemic in 2006, and in 2013 was still among the top 12 endemic countries. ${ }^{1}$ Since 2010, intense leprosy controls take place in Papua to ensure complete eradication. Despite these efforts, Papua was still considered as one of the largest leprosy pockets in Indonesia in 2014. ${ }^{2}$ The elimination of leprosy from Papua province requires further research directed toward the identification of risk factors involved in the transmission of leprosy.

Factors affecting leprosy include infectious agents, genetic, and environmental factors. ${ }^{3}$ In general, the transmission of leprosy does not involve any vectors and is suspected to occur through droplets or fluids arising from the infected patient's body. A study revealed that Mycobacterium leprae is transmitted via the respiratory 
tract. ${ }^{4} M$. leprae can be detected in skin lesions as well as nasal passages of infected individuals. ${ }^{5}$ Group of individuals sharing the same household with the leprosy patients are more susceptible to the infection. ${ }^{6}$ In this era of leprosy elimination, exposure to $M$. leprae in household contacts in the areas that supply a large number of leprosy cases should be evaluated as per the new models of study.

For various host factors affecting leprosy, a study conducted in Kuwait reported higher incidences of diabetes in leprosy patients as compared to the control group. ${ }^{7}$ In other diseases involving mycobacterial infection like tuberculosis, diabetes mellitus has been found to be associated with increased risk of Mycobacterium tuberculosis infection. ${ }^{8}$ Unfortunately, there is not much information available on the association of blood sugar levels and the risk of $M$. leprae infection. According to the WHO data, the global prevalence of diabetes mellitus is $6.4 \%$ which will reach $7.7 \%$ by $2030 .{ }^{6}$ Thus, it can be hypothesized that blood glucose levels could be one of the important factors associated with leprosy which will be explored in the present study.

$M$. leprae is a slow replicating bacterium which is generally uncultivable in microbiological culture medium. A study has reported the use of armadillos for the proliferation of this pathogen but this procedure is not feasible for the regular diagnostic. ${ }^{9}$ The diagnostic process commonly used in clinics for leprosy detection involves Ziehl-Neelsen staining of slit-skin specimens obtained from leprosy patients. Alternatively, molecular biology approach using polymerase chain reaction $(P C R)$ allows for the detection of $M$. leprae in symptomatic and asymptomatic patients. Detection of M. leprae using PCR also helps to check its transmission from patients to asymptomatic household contacts. ${ }^{10}$

Since the transmission of $M$. leprae occurs via respiratory tract, it becomes highly important to check the exposure of $M$. leprae in household contacts in the endemic areas. ${ }^{4}$ This study was aimed to identify the risk factors for the transmission, both environmental factors and host factors like blood glucose levels were studied.

\section{METHODS}

\section{Study population}

This cross-sectional study was carried out from March to November 2015 in the villages of Jayapura district of Papua province that served as the main pocket of leprosy in Indonesia. Subjects of this study were household contacts with leprosy patients. Leprosy patients were identified by well-trained health care workers based on cardinal signs as well as ZiehlNeelsen staining, living in Jayapura city for more than two years, and completion of the study process, such as interview, house visit, and specimen collection. All the leprosy patients were then confirmed using PCR. For each leprosy patient, up to four household contacts that had no symptom were included in the study. The inclusion criteria of the household contact group were people living with leprosy patients in the same house for more than 8 months and healthy individuals without any symptoms of leprosy. The exclusion criteria for both leprosy cases and household contacts were individuals with severe chronic diseases, influenza, mucus hypersecretion, or undergoing tuberculosis treatment. Household contacts with low quality of the extracted DNA were also excluded. The study was approved by the Ethical Committee of National Institute of Health Research and Development (No: LB.02.01/5.2/ KE.155/2015). All the participants approved the research protocol and gave written informed consent.

\section{Sample collection}

Slit-skin biopsies and nasal swab specimens were collected from index cases to confirm the diagnosis. Nasal swab specimens were collected from household contacts. Postnasal cleaning was carried out with sterile cotton bud and nasal swab specimens were collected using a sterile cotton swab. Skin biopsies were taken from active lesions or ears using sterile scalpel by trained physicians from leprosy patients During transportation from the field to the laboratory, both nasal swab and biopsies were preserved in cryotubes containing $300 \mu \mathrm{l}$ phosphate buffer saline. The samples were transported to Microbiology Laboratory in Jayapura and were kept in icebox at $4-8^{\circ} \mathrm{C}$ before transferring to bio-refrigerator for storage. Assays for DNA extraction, PCR, and blood analysis were performed at Microbiology Laboratory of Institute of Health Research and Development of Papua. Sanger sequencing was carried out at Center of Research and Development of Biomedical and Health Basic Technology, Jakarta.

\section{DNA extraction from nasal swab and slit-skin samples}

QIAamp ${ }^{\circledR}$ DNA Mini Kit (cat.51304, QIAGEN, Germany) was used for DNA extraction from nasal swab according to the manufacturer's protocol with slight 
modifications which was sonicated at $75 \%$ amplitude for 1 min before extraction. ${ }^{11}$ In addition to this, $20 \mu \mathrm{l}$ lysozyme was added to the lysis buffer. ${ }^{12}$

\section{PCR}

The primers LP1 (5'-TGCATGTCATGGCCTTGAGG-3') and LP2 (5'-CACCGATACCAGCGGCAGAA-3') $)^{13}$ were used to amplify a 143 bp segment of $M$. leprae present in the samples from leprosy patients and household contacts. PCR was performed with a reaction cocktail consisting of $4 \mu$ l template, $1 \mu$ L LP1 primer, $1 \mu$ L LP2 primer, $1 \mu$ l double distilled water, and $13 \mu \mathrm{l}$ of PCR Master Mix (GoTaq ${ }^{\circledR}$ Green Mastermix Promega Corporation, USA). C1000 Thermal Cycler (Biorad, USA) was used for PCR with following cycle conditions: initial cycle of $3 \mathrm{~min}$ at $95^{\circ} \mathrm{C}$, 35 cycles with each cycle consisting of $30 \mathrm{sec}$ at $94^{\circ} \mathrm{C}$, $30 \mathrm{sec}$ at $58^{\circ} \mathrm{C}, 60 \mathrm{sec}$ at $72^{\circ} \mathrm{C}$, and a final extension of 10 min at $72^{\circ} \mathrm{C}$. The resulting $P C R$ products were separated on a $2 \%$ agarose gel, run in tris-borate-EDTA buffer at 100 volts for 1 hour. The gels were stained in SYBR safe for visualization of bands. A 100 bp DNA Ladder (Invitrogen Life Technologies, Brazil) was used as molecular marker. Both positive and negative controls were included in each agarose gel. For positive control, $4 \mu \mathrm{l}$ of DNA extracted from skin lesions of confirmed leprosy patient was used, while $5 \mu \mathrm{l}$ of nuclease-free water (Promega, USA) served as a negative control. DNA spectrophotometry was then used to examine the extracted DNA. The negative results in electrophoresis with low purity in spectrophotometry (1.7-2.0 on $A$ $260 / 280$ ) were concluded as low quality of DNA.

\section{DNA sequencing and analysis}

The presence of $M$. leprae in specimens was obtained by sequencing of $P C R$ products. $P C R$ positive products obtained from both leprosy patients that was diagnosed with clinical symptoms as well as asymptomatic household contacts were sequenced using Sanger sequencing machine (Applied Biosystem). The sequencing was performed according to the protocol of BigDye ${ }^{\mathrm{TM}}$ Terminator v3.1 Cycle Sequencing Kit (Applied Biosystems, USA) with LP1 (upstream) and LP2 (downstream) primers. For analysis, basic local alignment search tool (BLAST) was performed to match the sequence of samples to the GenBank ${ }^{\circledR}$ sequences.

\section{Risk factor analysis}

Various risk factor parameters were also evaluated to study the transmission of $M$. leprae in household contacts. This included random blood glucose, ethnic, sleeping proximity to leprosy patient (in 1 bedroom or separate bedroom), relatives, and period of living together with the patients. Interviews using questionnaire tool to observe the demographic data of patients as well as the risk factors habit such as sleeping proximity to leprosy case, relatives, and period of living together with the patients were performed for data collection.

\section{Data analysis}

The presence of a single band of PCR product (143 bp) corresponding to M. leprae DNA marked the clinical samples positive for $M$. leprae detection, while the absence of amplification band as compared to PCR controls marked them as negative. The sequenced data were analyzed using BLAST to match the sequence of the samples with the GenBank ${ }^{\otimes}$. The epidemiology data was analyzed using univariate to describe the characteristics as well as bivariate to analyze the association of risk factors with SPSS software, version 21 (IBM Corp, USA).

\section{RESULTS}

There were some leprosy patients that did not live together with four persons in one house. Of total 134 household contacts, there were 27 persons who were

Table 1. Characteristics of the leprosy patients

\begin{tabular}{lc}
\hline Characteristics & $\mathrm{n}(\%)(\mathrm{N}=35)$ \\
\hline Male sex & $21(60.0)$ \\
\hline Signs & $31(88.6)$ \\
\hline Patch & $2(5.7)$ \\
\hline Infiltrate & $2(5.7)$ \\
\hline Nodule erythema & \\
\hline Duration of symptoms & $26(74.3)$ \\
\hline 1 year & $9(25.7)$ \\
\hline$>1$ year & \\
\hline Classification of leprae & $31(88.6)$ \\
\hline MB & $4(11.4)$ \\
\hline PB & $7(20.0)$ \\
\hline Density housing & $28(80.0)$ \\
\hline High & \\
\hline Low
\end{tabular}

$\mathrm{MB}=$ =multibacillary leprosy; $\mathrm{PB}=$ paucibacillary leprosy

Low-density housing was defined as $<1$ residents per $8 \mathrm{~m}^{2}$, otherwise it would be considered as high 
Table 2. Risk factors analysis for $M$. leprae detection in household contacts

\begin{tabular}{|c|c|c|c|c|c|}
\hline \multirow{2}{*}{ Risk factors } & \multicolumn{2}{|c|}{ M. leprae, $\mathrm{n}(\%)(\mathrm{N}=107)$} & \multirow{2}{*}{ OR } & \multirow{2}{*}{$95 \% \mathrm{Cl}$} & \multirow{2}{*}{$p$} \\
\hline & Positive & Negative & & & \\
\hline \multicolumn{6}{|l|}{ Blood glucose } \\
\hline Normal & $16(15.0)$ & $55(51.4)$ & 1.804 & $0.603-5.399$ & 0.440 \\
\hline High & $5(4.7)$ & $31(29.0)$ & & & \\
\hline \multicolumn{6}{|l|}{ Ethnic } \\
\hline Papua & $20(18.7)$ & $74(69.2)$ & 3.243 & $0.398-26.457$ & 0.456 \\
\hline Non-Papua & $1(0.9)$ & $12(11.2)$ & & & \\
\hline \multicolumn{6}{|c|}{ Period of living together } \\
\hline$\leq 1$ year & $1(0.9)$ & $33(30.8)$ & 12.45 & $1.595-97.20$ & 0.002 \\
\hline$>1$ year & $20(18.7)$ & $53(49.5)$ & & & \\
\hline \multicolumn{6}{|c|}{ Sleeping proximity to a leprosy case } \\
\hline In 1 bedroom & $4(3.7)$ & $10(9.3)$ & 1.788 & $0.501-6.388$ & 0.468 \\
\hline Separate bedroom & $17(15.9)$ & $76(71.0)$ & & & \\
\hline \multicolumn{6}{|l|}{ Relatives } \\
\hline Familial & $9(8.4)$ & $39(36.4)$ & 0.904 & $0.345-2.367$ & 0.518 \\
\hline Non-familial* & $12(11.2)$ & 47 (43.9) & & & \\
\hline
\end{tabular}

OR=odds ratio; $\mathrm{Cl}=$ confidence interval

*Non-familial=non-first degree relative such as cousin or other relative such as neighbor. The association analysis was run using Cochran-MantelHaenszel statistics to observe the OR of the risk factors

excluded ( 8 persons declined to participate and 19 persons had low quality of DNA). Hence, there were 107 household contacts from 35 leprosy patients included in this study. The leprosy cases were involved in point of care, in-depth interviews, and sample collection. For the patients who signed informed consent form, house visits were conducted for in-depth interviews and sample collection. Table 1 lists the characteristics of 35

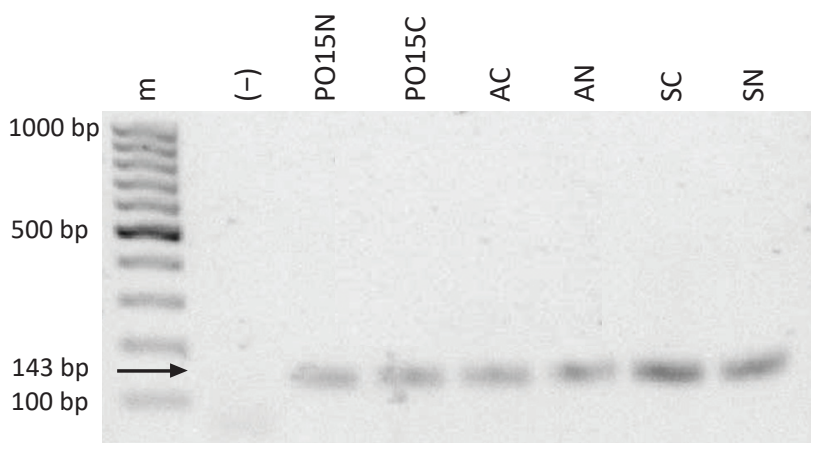

Figure 1. Agarose gel electrophoresis for polymerase chain reaction (PCR) assay. The size of target sequence amplified using LP1 and LP2 primers is $143 \mathrm{bp}$. Three index cases are represented with codes $\mathrm{P}, \mathrm{A}$, and $\mathrm{S}$ at the first character of the code above; $C$ at the last character indicates the slit-skin samples and $\mathrm{N}$ indicates the nasal swab samples. Code $\mathrm{m}$ indicated $100 \mathrm{bp}$ marker. No band was observed for negative control and the presence of $143 \mathrm{bp}$ band corresponding to presence of Mycobacterium leprae. bp=base pair leprosy cases. The results listed in Table 1 reveal that most of the leprosy patients included in the study were male and having main symptom of patch for less than 1 year. Multibacillary patients were higher in number than paucibacillary. Most of these patients lived in houses with a density $\geq 8 \mathrm{~m}^{2}$ floor area, which was still within the standard criteria for a healthy house.

PCR assay on nasal swab specimens of household contacts further showed that $19.62 \%(n=21)$ of household contacts were exposed to $M$. leprae. The presence of $143 \mathrm{bp}$ of target sequence in $\mathrm{PCR}$ products was confirmed using agarose gel electrophoresis (Figure 1). To confirm these results, sequencing was performed on randomly selected $P C R$ positive samples. For both index cases as well as household contacts, eight samples were randomly selected and sequenced on Sanger cycle sequencing machine. The results from BLAST studies showed a similarity of $\geq 90 \%$ between PCR positive samples and $M$. leprae.

Table 2 lists the characteristics and transmission risk factors associated with household contacts included in the study. Field observations and in-depth interviews indicated that most of the participants recruited as household contacts were females. Distant family members dominated the list as compared to first-degree relatives. Most of these household contacts were living 
with the patients in different bedrooms for more than a year. Most of them showed normal blood glucose levels as indicated by blood glucose examination results. The household contacts that live more than 1 year with the leprosy patient showed that the risk of having $M$. leprae were 12 times higher than those living away from the patient. Other factors such as blood glucose, ethnic, sleeping proximity to leprosy patient, and relatives give no effect to the $M$. leprae detection in household contacts.

\section{DISCUSSION}

We are interested in elucidating the characteristics of leprosy cases living in Jayapura and the transmission of $M$. leprae from these patients to household contacts. A molecular biology approach was used to detect the presence of $M$. leprae in asymptomatic household contacts. More than one nuclear family living together under the same roof is a common cultural practice in Papua.

PCR studies showed that $19.62 \%$ of household contacts were positive for $M$. leprae presence. This technique has been previously used for different types of samples including urine, ${ }^{14}$ blood, ${ }^{15}$ saliva, ${ }^{16}$ archeological skeletal, ${ }^{17}$ and nasal swab. ${ }^{18,19}$ Nasal swab specimens from leprosy patients and household contacts were collected for PCR assay. In 1993, a study conducted in Makassar reported $7.8 \%$ of 1,228 cases, including both household contacts and residents having no interaction with patients in endemic areas, to be PCR positive. ${ }^{20}$ In another study by Klatser et al, ${ }^{21}$ PCR was applied for $M$. leprae detection in nasal swab specimens which were collected during a total population survey conducted in two villages located in South Sulawesi, another leprosy endemic area in Indonesia. The results of that study confirmed the nasal carriage of $M$. leprae among the general population in an area endemic for leprosy and this feature was not restricted to few patients. ${ }^{21}$

The percentage of household contacts with positive for $M$. leprae detection in the present study is similar to the study conducted in a hyper-endemic leprosy area in Brazil. The authors reported the presence of bacillary DNA in $23.89 \%$ of asymptomatic household contacts using qPCR. ${ }^{22}$ Another study in Colombia, combined three methods of detection to evaluate $M$. leprae detection in household contacts. For 402 household contacts linked to 104 index patients included in the study, $13.4 \%$ showed IgM seropositivity, 9.4\% were Mitsuda-negative, and 5.5\% were found positive using PCR of nasal swab specimens. ${ }^{23}$ In another study conducted in Columbia post-elimination, 16\% (18 of 113) household contacts were found PCR positive for the presence of $M$. leprae in the nasal swab samples. Genotyping of the $M$. leprae strain present in the index cases and household contacts was performed and similarities was reported between the two strains in both groups. ${ }^{24}$

In Brazil, da Costa Martins et $\mathrm{al}^{18}$ used a different approach for PCR where serological examination of the phenolic glycolipid 1 antigen was used to detect the transmission of $M$. leprae from index case to contact case. Although, there was sera positive in household contacts, the clinical form was not appeared as in the index cases; nevertheless, a tendency higher rate of multibacillary for index cases was reported. The clinical form of index case was unrelated to serum positivity of contact as this index case was not the primary case or the source of transmission for the secondary case. ${ }^{18}$ In a study by Pattyn et al, ${ }^{19} 23$ nose swab specimens obtained from eight multibacillary patients were examined and found three cases of leprosy-positive. This study also used PCR based method for detection of M. leprae in nasal swab samples.

The rate of DNA detection in nasal swabs obtained from contacts varies from 1 to $10 \%$, which sometimes depends on the clinical form of the index cases. However, the high rate of $M$. leprae detection among healthy populations using $P C R$ test questions the feasibility of this method as a diagnostic tool for leprosy risk evaluation, particularly for this area of sample collection. A separate study showed that the household contacts with positive anti-phenolic glycolipid-I test ${ }^{3}$ from blood samples and PCR assay showed a higher risk of leprosy development. ${ }^{25}$ Thus, combining PCR and serological test for leprosy detection can increase the accuracy of the disease prediction. For future studies, accurate prediction of risk for developing leprosy in household contacts might be a useful tool for deciding priority for chemoprophylaxis blanket area and providing early treatment before any spread out of leprosy manifestation. ${ }^{26}$ The transmission of leprosy can be greatly curbed by providing necessary treatment at early stages.

Various risk factors affecting leprosy exposure in household contacts were also evaluated in the present study (Table 2). These included blood glucose levels, 
ethnicity, period of living together with the patients, sleeping proximity with the leprosy case, and relatives. Among these, period of living together with the patient for more than a year increased the risk of $M$. leprae detection by 12.45 times $(p=0.002)$. Some studies have shown that $M$. leprae is transmitted via inhalation, ${ }^{19,25}$ which might explain the correlation observed between the period of living together and exposure to $M$. leprae. The results of this study also revealed that most of the index cases were multibacillary that have a higher risk of transmission than paucibacillary because multibacillary patients carry the bacteria in their nasal mucosa. ${ }^{25}$

In Papua, living together with more than one nuclear family is a common cultural. Most of the houses included in the study has $8 \mathrm{~m}^{2}$ or more floor area which meets the criteria of a healthy house. However, the surrounding environment observed during this study reported the study site to be one of the dirty and crowded areas of Jayapura. Association between house conditions and risk for leprosy development has been discussed in previous studies. According to Pescarini et al, ${ }^{27}$ socio-economic status including house conditions strongly affects leprosy transmission. The results from another study conducted in a different population indicated that socio-economic conditions such as sanitation, house conditions, and economic status increase the risk of leprosy development. ${ }^{28}$

Household contact is the group at highest risk for leprosy transmission. This idea is supported by the findings of a cohort study conducted in Rio de Janeiro from 1987-2010 which revealed that 4.9\% of household contacts developed leprosy. ${ }^{14}$ In the present study, positive results obtained from PCR of nasal swab specimens of household contacts indicated the presence of active bacterial transmission via inhalation in Papua. Based on these findings, we can predict that about $19.6 \%$ of household contacts found positive in PCR studies are at higher risk of developing leprosy in the area of study. Since Indonesia aims to reach leprosy elimination by 2020 , intensive and breakthrough approaches such as chemoprophylaxis blanket, intensive case finding, and integrated family health movement should be applied in Papua to cut this transmission chain and endorse the health quality in this leprosy pocket.

The limitations of this study are only four household members were recruited from one confirmed case; a single detection method based on PCR, and a small sample size. Furthermore, PCR positive samples were randomly selected for Sanger sequencing for cases as well as household samples. However, this study shows that PCR can effectively detect $M$. leprae in nasal swab of household contacts and it can be utilized as an important tool for contact survey in combination with another assay for detection. In this leprosy elimination era, household contact surveys are very important especially in areas like Papua, one of the biggest leprosy pockets in Indonesia. The identification of new and efficient diagnostic tools for $M$. leprae detection in asymptomatic household contacts will support the efforts aimed at breaking the chain of transmission in endemic areas.

In conclusions, $M$. leprae was detected in $19.6 \%$ of asymptomatic household contacts. Among the various risk factors studied for leprosy transmission, duration of living together with the patient significantly increased the risk of $M$. leprae transmission.

\section{Conflicts of Interest}

The authors affirm no conflict of interest in this study.

\section{Acknowledgments}

We acknowledge the support provided by Papua Health Office, Hamadi Point of Care, and Vera Yoku during field work.

\section{Funding Sources}

This research was funded by National Institute of Health Research and Development through junior researcher research competition program.

\section{REFERENCES}

1. World Health Organization. Integrating neglected tropical diseases into global health and development: fourth WHO report on neglected tropical diseases. Geneva: World Health Organization; 2017. Available from: https://unitingtocombatntds. org/wp-content/uploads/2017/11/4th_who_ntd_report.pdf.

2. Purnomo, Giyai A, Rumainum A, editors. Leprosy annual report 2014. 1st ed. Papua Provincial Health Office. Leprosy annual report 2014. 1st ed. Purnomo, Giyai A, Rumainum A, editors. Jayapura: Provincial Health Office of Papua; 2014. p. 3-5.

3. Düppre NC, Camacho LA, Sales AM, Illarramendi X, Nery JA, Sampaio EP. Impact of PGL-I seropositivity on the protective effect of BCG vaccination among leprosy contacts: a cohort study. PLoS Negl Trop Dis. 2012;6(6):e1711.

4. Job CK, Jayakumar J, Kearney M, Gillis TP. Transmission of leprosy: a study of skin and nasal secretions of household contacts of leprosy patients using PCR. Am J Trop Med Hyg. 2008;78(3):518-21.

5. Scollard DM, Adams LB, Gillis TP, Krahenbuhl JL, Truman RW, Williams DL. The continuing challenges of leprosy. Clin Microbiol Rev. 2006;19(2):338-81.

6. Sarno EN, Duppre NC, Sales AM, Hacker MA, Nery JA, de Matos HJ. Leprosy exposure, infection and disease: a 25year surveillance study of leprosy patient contacts. Mem Inst Oswaldo Cruz. 2012;107(8):1054-9.

7. Saraya MA, Al-Fadhli MA, Qasem JA. Diabetic status of patients with leprosy in Kuwait. J Infect Public Health. 2012;5(5):360-5. 
8. Casqueiro J, Casqueiro J, Alves C. Infections in patients with diabetes mellitus: a review of pathogenesis. Indian J Endocrinol Metab. 2012;16 Suppl 1(Suppl 1):S27-36.

9. Williams DL, Pittman TL, Deshotel M, Oby-Robinson S, Smith I, Husson R. Molecular basis of the defective heat stress response in Mycobacterium leprae. J Bacteriol. 2007;189(24):8818-27.

10. Caleffi KR, Hirata RD, Hirata MH, Caleffi ER, Siqueira VL, Cardoso RF. Use of the polymerase chain reaction to detect Mycobacterium leprae in urine. Braz J Med Biol Res. 2012;45(2):153-7.

11. van Helden PD, Victor TC, Warren RM, van Helden EG. Isolation of DNA from Mycobacterium tuberculosis. In: Parish T, Stoker N, editors. Methods in Molecular Medicine. 2nd ed. New Jersey: Humana Press Inc; 2001. p. 19-29.

12. Imaeda T, Kirchheimer WF, Barksdale L. DNA isolated from Mycobacterium leprae: genome size, base ratio, and homology with other related bacteria as determined by optical DNA-DNA reassociation. J Bacteriol. 1982;150(1):414-7.

13. Donoghue HD, Holton J, Spigelman M. PCR primers that can detect low levels of Mycobacterium leprae DNA. J Med Microbiol. 2001;50(2):177-82.

14. Parkash O, Singh HB, Rai S, Pandey A, Katoch VM, Girdhar BK. Detection of Mycobacterium leprae DNA for $36 \mathrm{kDa}$ protein in urine from leprosy patients: a preliminary report. Rev Inst Med Trop Sao Paulo. 2004;46(5):275-7.

15. Almeida EC, Martinez AN, Maniero VC, Sales AM, Duppre NC, Sarno EN, et al. Detection of Mycobacterium leprae DNA by polymerase chain reaction in the blood and nasal secretion of Brazilian household contacts. Mem Inst Oswaldo Cruz. 2004;99(5):509-11.

16. Rosa FB, Souza VC, Almeida TA, Nascimento VA, Vásquez FG, Cunha M, et al. Detection of Mycobacterium leprae in saliva and the evaluation of oral sensitivity in patients with leprosy. Mem Inst Oswaldo Cruz. 2013;108(5):572-7.

17. Suzuki K, Takigawa W, Tanigawa K, Nakamura K, Ishido Y, Kawashima A, et al. Detection of Mycobacterium leprae DNA from archaeological skeletal remains in Japan using whole genome amplification and polymerase chain reaction. PLoS One. 2010;5(8):e12422

18. da Costa Martins AC, Miranda A, de Oliveira MLW del R, Bührer-
Sékula S, Martinez A. Nasal mucosa study of leprosy contacts with positive serology for the phenolic glycolipid 1 antigen. Braz J Otorhinolaryngol. 2010;76(5):579-87.

19. Pattyn SR, Ursi D, leven M, Grillone S, Raes V. Detection of Mycobacterium leprae by the polymerase chain reaction in nasal swabs of leprosy patients and their contacts. Int J Lepr Other Mycobact Dis. 1993;61(3):389-93.

20. de Wit MY, Douglas JT, McFadden J, Klatser P. Polymerase chain reaction for detection of Mycobacterium leprae in nasal swab specimens. J Clin Microbiol. 1993;31(3):502-6.

21. Klatser PR, van Beers S, Madjid B, Day R, de Wit MY. Detection of Mycobacterium leprae nasal carriers in populations for which leprosy is endemic. J Bacteriol. 1993;31(11):2947-51.

22. Gama RS, Gomides T, Gama C, Moreira S, de Neves Manta FS, de Oliveira $L$, et al. High frequency of $M$. leprae DNA detection in asymptomatic household contacts. BMC Infect Dis. 2018;18(1):153.

23. Cordona-Castro N, Beltran-Alzate J, Manrique-Hernández R. Survey to identify Mycobacterium leprae -infected household contacts of patients from prevalent regions of leprosy in Colombia. Mem Inst Oswaldo Cruz. 2008;103(4):332-6.

24. Romero-Montoya M, Beltran-Alzate JC, Cardona-Castro N. Evaluation and monitoring of Mycobacterium leprae transmission in household contacts of patients with Hansen's disease in Colombia. PLoS Negl Trop Dis. 2017;11(1):e0o05325.

25. Martinez AN, Talhari C, Moraes MO, Talhari S. PCR-based techniques for leprosy diagnosis: from the laboratory to the clinic. PLoS Negl Trop Dis. 2014;8(4):e2655.

26. Mieras LF, Taal AT, van Brakel WH, Cambau E, Saunderson PR, Smith WC, et al. An enhanced regimen as post-exposure chemoprophylaxis for leprosy: PEP++. BMC Infect Dis. 2018;18:506.

27. Pescarini JM, Strina A, Nery JS, Skalinski LM, Andrade K, Penna $M$, et al. Socioeconomic risk markers of leprosy in high-burden countries: a systematic review and meta-analysis. PLoS Negl Trop Dis. 2018;12(7):e0006622.

28. Moet F, Meima A, Oskam L, Richardus JH. Risk factors for the development of clinical leprosy among contacts, and their relevance for targeted interventions. Lepr Rev. 2004;75(4):310326. 